\title{
Review: Silica Aerogel as a Viable Absorbent for Oil Spill Remediation
}

\author{
Abiodun Paul Olalekan', Adewunmi Oluwasogo Dada², Olusola Adedayo Adesina1 \\ ${ }^{1}$ Department of Chemical Engineering, Landmark University, Omu-Aran, Nigeria \\ ${ }^{2}$ Department of Industrial Chemistry, Landmark University, Omu-Aran, Nigeria \\ Email: olalekanabiodun@hotmail.com
}

Received 20 October 2014; revised 14 November 2014; accepted 4 December 2014

Copyright (C) 2014 by authors and Scientific Research Publishing Inc.

This work is licensed under the Creative Commons Attribution International License (CC BY).

http://creativecommons.org/licenses/by/4.0/

c) (i) Open Access

\begin{abstract}
The review article reflects on the potential of silica aerogel as viable absorbents for spilled crude oil. Reported oil absorption capacity of silica aerogel shows it has a future in polluted site clean-up. The review presents the various dynamics of oil spill, conventional clean-up technologies and silica aerogel synthesis techniques. It also highlights some investigations of oil spill sorption using aerogels. The future prospect of rice husk as a cheaper source silica aerogel is also considered.
\end{abstract}

\section{Keywords}

Oil Spill, Remediation, Absorbent, Silica Aerogel, Rice Husk, Drying

\section{Introduction}

Oil is the life wire of our today's world. Oil is used to fuel vehicles, lubricate machinery, make plastics, heat homes, make plastics, inks, fertilizers, vanishes, paints, etc.

With the increasing demand for energy by emerging economies, the oil production rate (crude oil, shale oil, oil sands, and natural gas liquids) has been put at 86.91 million barrels per day [1]. As a result, new technologies are being developed to facilitate faster exploration.

The environment, however, has borne the brunt of oil exploration and transportation for several decades as oil spills have contaminated coastal waters and lands. Oil spill, though, usually applied to marine oil spills in which oil is released into ocean and coaster waters, it may also be on land. Oil spill may be due to releases of oil crude oil from tankers, offshore platforms, drilling rigs and wells, as well as spills of refined petroleum products (such as gasoline, diesel, etc.) and their by-products, heavier fuels, or the spill of any other refuse or waste oil.

Oil and water do not mix. Upon spillage, the oil forms a thin and often a large layer on the surface of the water. 
Oil spills harm aquatic life. Fishes, birds, mammals and reptiles which consume the oil suffer serious health problems and furred animals exposed to the oil have their mobility and body temperatures affected [2]. Most birds that are coated in oil would not survive if not cleaned. Plants growing in or near the water can be destroyed as the sunlight required for photosynthesis is blocked. This kills plant growing in the water. Thus, pollution resulting from oil spill adversely affects the economy, leisure and tourism [3].

\section{History of Oil Spill}

The first major commercial oil spill was in 1967 in the United Kingdom. It was due to an accident in which a super tanker, Torrey Canyon ran aground on Pollard Rock off the coast of England [4]. Other famous spills include the Kuwait oil spill (1989) with 10 million barrels of oil spilled [2], the Exxon-Valdez (1989) in which 55 million gallons of crude oil was spilled into Prince William Sound's Bligh Reef in Alaska. The Deepwater Horizon explosion, also known as the BP oil spill which started in April 20, 2010 and continued for another 87 days is when an oil rig, Deep Horizon exploded. About 4.9 billion gallons of oil was spilled [5].

The following processes occur when oil spills based on the water source and the type and amount of spilled oil [6]:

1) The most common occurrence is the spread of the oil over the water surface. Light oils such as gasoline spread faster than heavy crude. The rate of spread is also dependent on the current, wind and temperatures. This spread makes it expedient to contain the spill as quickly as possible.

2) There is a tendency for the oil to sink to the bottom of the water. While the density of oil range from 0.85 $1.04 \mathrm{~g} / \mathrm{cm}^{3}$, most oil densities fall between 0.90 to $0.98 \mathrm{~g} / \mathrm{cm}^{3}$ range. Ocean water has a density between 1.02 and $1.03 \mathrm{~g} / \mathrm{cm}^{3}$ depending on the salt concentration. River water, however, has a density of $1.0 \mathrm{~g} / \mathrm{cm}^{3}$ this means heavy oil, with a density of $1.01 \mathrm{~g} / \mathrm{cm}^{3}$ would float in ocean water but sink in a river.

3) The oil can be moved by the flow of river and the surge of tides of oceans.

4) Natural bacteria can digest the hydrocarbon and convert them to $\mathrm{CO}_{2}$ and water. This can be employed for bioremediation of an oil spill site.

5) Some oil will evaporate.

6) The oil can undergo weathering processes. This includes evaporation, dissolution, dispersion and adsorption onto suspended materials, agglomeration etc.

7) Oxidation of the hydrocarbon by oxygen. It's a process that slowly breaks down the hydrocarbon.

8) Emulsification of the oil. This results from the suspension of either the oil in water or water in the oil. The water-in-the-oil emulsion is more stable and can persist for years. Water-in-oil often consists of 50 to 80 percent water and the water appears reddish-brown and feels greasy due to the presence of oil.

\section{Current Methods of Oil Spill Cleanup}

On the broader basis, oil spill response methods are divided into three main categories; mechanical recovery, where oil is contained in an area using boom or natural barriers and removed using skimmers and pumps; non mechanical recovery where chemical counter measures, basically dispersals, burning, or bioremediation are used to degrade or disperse the oil layer; and manual recovery where oil is removed using simple hand tools and techniques such as pails, shovels or nets. Each of these methods is discussed below.

\subsection{Containment with Oil Booms}

It is imperative to quickly corral off the oil released into the body of water to minimize its spread and to facilitate cleanup and removal. This is achieved through a quick and skillful deployment of containment booms. Boom materials are highly coloured for ease of recovery and to help the crews spot any break in line [7]. Booms are among the most commonly used tools in oil spill response there are three main types of booms. A hard boom in its simplest form is made of rugged fabric with buoyant fillers fitted to its side to make it float above water and a heavy bottom to make it sink with sub surface skirt [7]. Sorbent booms, which are made from materials that can absorb oil, are most effective on thin, light oil slicks. The third kinds of booms are the fire booms. They are similar to hard booms, though made of metals. Fire booms are used to contain oil spill spills before setting it on fire. Fire booms are not frequently employed as hard and sorbent booms.

The ability of booms to contain spilled oil is hampered by water current, wave height, wind velocity and oil 
viscosity.

\subsection{Chemical Dispersant}

Dispersant are chemical formulations of surfactants, solvents and other additives which are sprayed on the oil slicks to accelerate its dispersion in water by reducing the surface tension between the water and oil. Composed of molecules with hydrophobic (oil-compatible) and hydrophobic (water-compatible) end, the dispersants link an oil droplet to a nearby water molecules and allow the natural agitation caused by waves and wind to pull the droplets apart into increasing smaller droplets. These small droplets eventually become heavier than water and therefore sink into the water column. The dispersants do not remove oil but rather the oil is transported to the bottom of the water. As such, aquatic life under water is still exposed to the deleterious effect of the oil and also the added dispersant.

\subsection{Bioremediation}

This involves the use of microbes, plants or fungi to clean up an oil contaminated environment. Scientists believe that naturally occurring microorganisms in the marine environment have the ability to degrade oil but limited availability of nutrients such as nitrogen and phosphorous hamper this ability [7]. This is the submission of a school of thought. Some other researchers believe that a formal seeding of the oil spills with more bacteria provides greater cleanup solution [8].

Bioremediation is a slow process. As such, applying it as an initial clean-up method is not encouraging. Another downside of the application of the bioremediation is that it is not practicable far offshore as the nutrients are diluted by high energy waves.

\subsection{Mechanical Recovery}

\subsubsection{Skimmers}

With the aid of booms, the spilled oil is corralled and prevented from spreading further. Then a skimming device is deployed to scoop the oil from the water surface.

Oil adheres to any surface it's in contact with. Skimmers always contain settling tanks so as to separate the oil and water in the tanks. The basic types of oil skimmers are the belt, brush/disk/drum, mop and floating suction. Generally, they work by moving on the oil as it adheres to the moving surface and scouping the oil as it adheres to the moving surface. The success of skimming depends on the thickness of the oil spill, the amount of debris in the water, the location and the weather conditions as skimming works best in calm weather.

\subsubsection{Burning}

Oil slick on the surface of water can be burnt off with the aid of burning, gelled fuel released from a helicopter or by releasing an ignition from vessel or other access point. Not all the oil can be removed by this process. Also, in burning, gases such as nitrogen and sulphur are released into the atmosphere. This causes additional environmental pollution.

\subsubsection{Sorbents}

Sorbents are solid porous materials obtained from organic and synthetic sources employed for recovering oil in preference to water. Sorbent materials can act either by adsorption or by absorption. In adsorption, the oil is preferably attached to the surface of the adsorbent while in absorption, the oil incorporated into the body of the material.

The sorbent is required to attract oil in preference to water i.e. it should be oleophilic and hydrophobic.

This research centers on the synthesis of a porous material for oil spill remediation. As such, much effort would be devoted to the review of previous works on the synthesis and characterization of sorbents for oil spill clean-up.

\section{Porous Materials for Oil Spill Remediation}

The application of sorbent materials is of interest due to the possibility of complete collection of oil from the spill site. These porous materials have an added advantage of possible recycling. Properties of good absorbent 
materials include hydrophobicity and olephilicity, high uptake capacity, high rate of uptake, retention time, oil recovery from absorbents and the reusability and biodegrability of the absorbents [9]. Therefore, to combat environmental pollution resulting from oil spill, there is a need to deepen research in the area of developing effective sorbent materials for oil spill remediation.

\subsection{Oil Sorption Phenomenon}

Sorption is commonly used for both absorption and adsorption. Absorption is the incorporation of a substance from one state into another (e.g. liquid being absorbed by a solid or gases absorbed by water). Adsorption is the physical adherence or bonding of ions and molecules into the surface of another molecule. An adsorbent is a porous solid material that is coated by a liquid on its surface including pores and capillaries without more than $50 \%$ in excess fluid [10]. In the process of adsorption, the adsorbate diffuses from the bulk stream to the external surface of the adsorbent, from where it migrates to the pore and finally adheres to the pore sites via van der Waals forces through physical adsorption or by chemical adsorption which is due to electron exchange among adsorbate and surface of adsorbent.

In absorption, the adsorbate permeates the body of the adsorbents. The driving force in this case is the capillary pressure gradient between the adsorbate and the adsorbent.

\subsection{Classification of Oil Sorbents}

According to Adebajo et al. (2003), porous absorbents for oil spill remediation can be categorized into three major classes namely inorganic mineral products, synthetic organic products and organic vegetable products.

Many organic or natural sorbents have been investigated for their possible use as adsorbents. Examples include barley straw [11], cotton [12], kappok, milk weed, rice straw and peat [13].

Researches have shown that these natural sorbents are biodegradable, economical but have poor buoyancy, low hydrophobicity and relatively low sorption capacity [9]. However, it has been reported that some of these natural sorbents such as kapok fibre, milkweed, cotton fiber and kenaf core have shown to sorb more oil than polypropylene materials that are normally used commercially [14].

Synthetic organic products are the most commonly used commercial sorbents in oil spill cleanup application. Examples include polypropylene and polyurethane. Polyurethane is said to have a sorption capacity of about100 times its weight of oil from oil-water mixture [9]. They are highly oleophilic and hydrophobic. Polypropylene non-woven sorbents have high oil sorption capacity and low water uptake [10]. The limitation of synthetic organic sorbents is their non-biodegradability. As such, disposing them in landfills and through incineration causes another form of pollution or is too expensive.

The mineral products employed as oil sorbents include silica aerogels, organoclays, exfoliated graphite, zeolite, pertite, vermiculites and diatomites. $\mathrm{CF}_{3}$-modified silica aerogel, which, according to Reynold and co-workers (2001), is very hydrophobic, completely absorbs oil at oil/aerogel ratio of up to 3.5. Hydrophobic pure-silica zeolite has equally given a good sorption of oil [9]. Poor biodegradability, poor buoyancy and oil sorption capacity are the limitations of mineral sorbents [10].

However, Adebajo et al. (2003) suggested the blending of these mineral products with other materials like cotton wool and activated carbon to enhance their performance.

\section{Silica Aerogels}

Aerogels are advanced nanoporous materials with an open structure and extremely high surface area. Silica aerogels have been thoroughly investigated. However, the possibility of increased fields of application has necessitated further research into their properties, synthesis and applications.

A typical silica aerogel consists of more than $96 \%$ air. The remaining $4 \%$ is a wispy silicon dioxide [15]. Silica aerogels are highly porous and optically transparent solid materials with pores less than 50 nanometers in diameter. The cross-linked internal structure gives aerogels highest surface area per gram of any known material which is put at $1000 \mathrm{~m}^{2} / \mathrm{g}$. Other important properties of silica aerogel include low density $\sim 50 \mathrm{~g} \cdot \mathrm{cm}^{-3}$, high optical transmission $\sim 90 \%$, high porosity $\sim 99 \%$, low thermal conductivity $\sim 0.05 \mathrm{~W} / \mathrm{m} \cdot \mathrm{K}$ and low dielectric constant $\sim 2[16]$. 


\section{Preparation and Characterization of Silica Aerogel}

Silica aerogels were first synthesized by Kistler in 1931. In recent times, silica has been prepared by methods such as vapour-phase reaction, sol-gel and thermal decomposition techniques. The most common method of synthesis is the sol-gel method.

The sol-gel method involves three primary steps.

1) Gel preparation

The silica gel is prepared by sol-gel process where a silica source is made to gel by the addition of catalyst. The gels are usually classified according to the dispersion medium used e.g. hydrogel or aquagel, alcogel and aerogel (for water, alcohol, and air respectively) [17].

In general, aerogel preparation starts with the preparation of the wet gel. The drying of the wet gel removes the solvent of the sol and leaves a structure filled with air in the pores. The procedure for the gel synthesis, referred to as the sol-gel synthesis, results in the formation of gel monolith. The sol formation could be a one or two steps synthesis. In the one-step sol-gel route, the sol is synthesized directly by the mixing of the silica precursor with acid or base catalyst in a solvent. The catalyst enhances the hydrolysis and condensation reactions leading to gel formation [16]. In the two-step sol synthesis, the precursor is first prepolymerised using an acid catalyst before a fluid condensation reaction under alkaline conditions.

Originally, alcogels are prepared from sodium silicate $\left(\mathrm{Na}_{2} \mathrm{SiO}_{3}\right)$ precursor. The demerit of using this precursor is the formation of sodium salts in the gel which requires extensive time consuming washing to remove. In recent times, the usual precursors for aerogel production are organic alkoxides, acetate and inorganic salts such as nitrates and chlorides. Silicon alkoxides are the most commonly used precursors. Examples of such include tetramethylorthosilicate, TMOS, $\left(\mathrm{Si}\left(\mathrm{OCH}_{3}\right)_{4}\right)$ and tetraethylorthosilicate, TEOS, $\left(\mathrm{Si}\left(\mathrm{OCH}_{2} \mathrm{CH}_{3}\right)_{4}\right)$. Many other alkoxides with various organic functional groups can be used to synthesize properties aerogels with specific to suit the required applications. The major reactions involved in the sol-gel formation are the hydrolysis and condensation processes of the precursors.

In the hydrolysis of process, the alkoxide group (-OR) in the tetraorthosilicate precursors is replaced with hydroxyl groups $(\mathrm{OH})$ from the solvent which can be alcohol, water, acetone etc. to form silica hydroxide (silanol).

Hydrophobic aerogels are obtained without surface chemical modifications from hydrophobic precursors while hydrophilic aerogels are obtained from hydrophilic precursors. Table 1 gives examples of hydrophobic and hydrophilic precursors.

Monomeric tetrafunctional and trifunctional silicon alkoxide precursors can be hydrolysed to produce silicate gels using a mineral acid (e.g. $\mathrm{HCl}, \mathrm{C}_{2} \mathrm{O}_{4} \mathrm{H}_{4}$ ) or a base (e.g. $\mathrm{NH}_{3}, \mathrm{NH}_{4} \mathrm{OH}$ ) as catalyst.

In the process of gel formation, hydrolysis and condensation are two reactions that occur. Reference [18] gave the schematic representation of the reactions as shown in Figure 1.

Sodium silicate $\left(\mathrm{Na}_{2} \mathrm{SiO}_{3}\right)$ is a cheap silica source. It reacts with water to give silicic acid source and the silicic acid polymerizes and forms silica gel as shown in the following reactions:

$$
\begin{gathered}
\mathrm{Na}_{2} \mathrm{SiO}+\mathrm{H}_{2} \mathrm{O}+2 \mathrm{HCl} \rightarrow \mathrm{Si}(\mathrm{OH})_{4}+2 \mathrm{NaCl} \\
n\left[\mathrm{Si}(\mathrm{OH})_{4}+(\mathrm{OH})_{4} \mathrm{Si}\right] \rightarrow n\left[(\mathrm{OH})_{3} \mathrm{Si}-\mathrm{O}-\mathrm{Si}(\mathrm{OH})_{3}\right]+\mathrm{H}_{2} \mathrm{O}
\end{gathered}
$$

Table 1. Precursors for silica aerogel synthesis (Gurav, et al., 2010).

\begin{tabular}{ll}
\hline \multicolumn{1}{c}{ Hydrophilic precursors } & \multicolumn{1}{c}{ Hydrophobic precursors } \\
\hline Tetramethylorthosilicate (TMOS) & Methyltrimethylorthosilicate \\
Tetraethylorthosilicate (TEOS) & Methyltriethylorthosilicate (MTES) \\
Sodium Silicate $\left(\mathrm{Na}_{2} \mathrm{SiO}_{3}\right)$ & \\
1) Aerogels-High Optical Transmission $(>90 \%)$ & 1) Aerogels-opaque \\
2) Density < $0.1 \mathrm{~g} / \mathrm{cm}^{3}$ & 2) Density $>0.1 \mathrm{~g} / \mathrm{cm}^{3}$ \\
3) Hard and brittle & 3) Soft and flexible \\
\hline
\end{tabular}




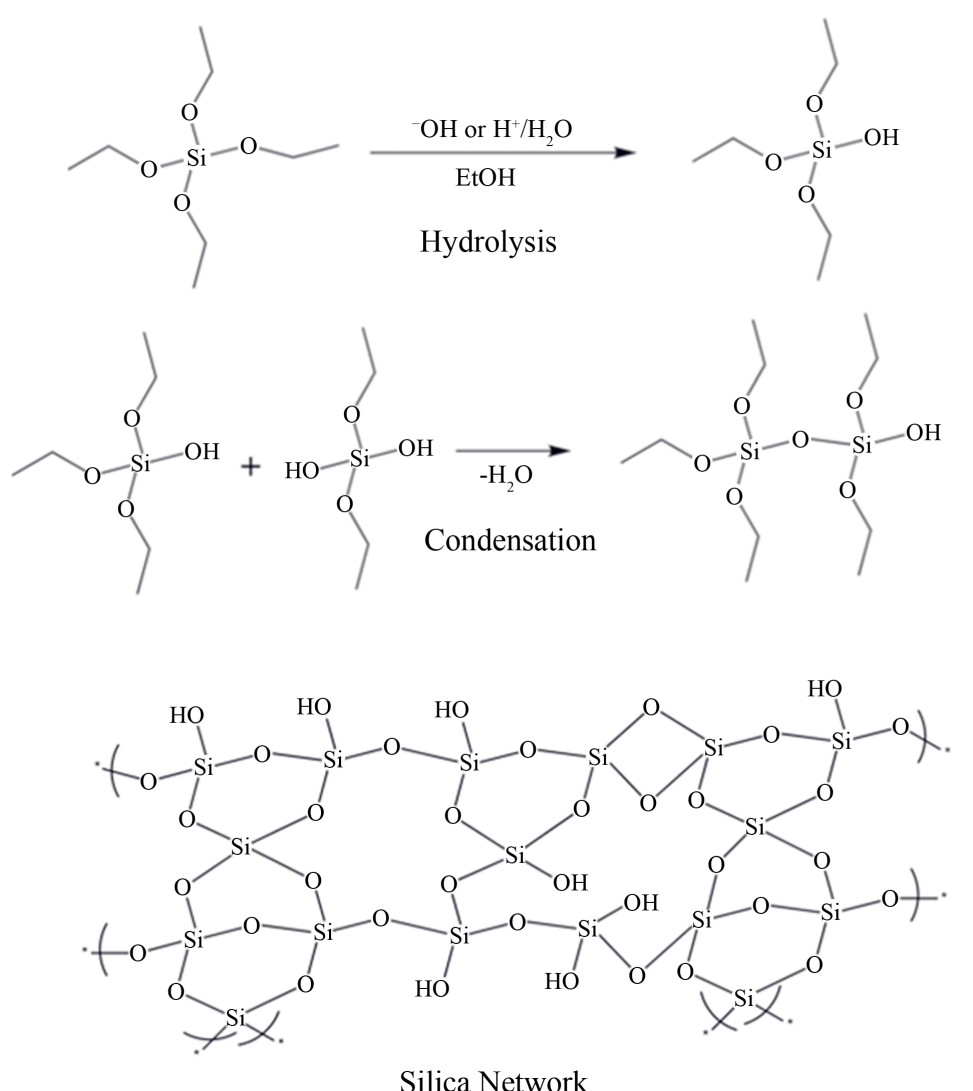

Figure 1. Sol-gel reactions during silica network formation: hydrolysis, condensation, and polymerization (Yang, 2011).

2) Aging of the gel

Here, the gel produced is soaked (aged) in the mother liquor for some days. The aging helps to strengthen the gel to prevent shrinkage during drying.

According to Dorcheh and Abbasi, (2008), two different mechanisms might operate during aging that affect the properties of the gel:

a) Neck growth between particles resulting from the precipitation of silica dissolved from particle surface.

b) Dissolution of small particles and precipitation onto larger ones.

Aging results in a porous solid in which solvent is trapped.

Several studies have shown that the composition, ph and time of aging affect the internal structure of the resulting aerogel such as the surface area, the strength and stiffness. Washing has been reported to increase the permeability of the gel. Several aging solutions have been used. Tetraethyorthosilicate (TEOS)-water-ethanol solutions have been used for aging of sodium silicate derived gels [19]. The gels were washed with $20 \%$ water and ethanol solution for 24 hours at $60^{\circ} \mathrm{C}$, then aging solution (70\% TEOS: ethanol, v/v) was used for $6-72$ hrs at $70^{\circ} \mathrm{C}$ followed by washing with ethanol and heptane. The use of solvents with low vapour pressure has been proposed [20]. Ionic liquids were used due to their low vapor pressures. During aging, the solvent evaporates and causes shrinkage of the network before the completion of aging process.

3) Drying of the gel

Several methods of drying have been researched. In drying the liquid in the pores is removed. Drying is carried out very carefully to avoid the collapse of the structure.

Drying is governed by capillary pressure [17]. The resulting gel after aging is filled with solvents in the pores. So, drying involves the removal of this majority of solvent.

In silica aerogel synthesis, various methods of drying have evolved out of the need to prevent cracking of the gel network due to capillary pressure. 
Since the diameters of the pores in the gel are in the order of nanometers, the hydrostatic pressure in the pores is very high. As the liquid evaporates, the static forces tend to pull the gel together and thus, the pores collapse.

Therefore, drying is carried out in a careful manner to prevent the shrinkage and collapse of the gel structure.

Various drying techniques have been developed to achieve this objective:

a) Supercritical drying of the alcogel

There are two methods of supercritical drying; high temperature (HTSCD) and low temperature (LTSCD).

In high temperature drying, the wet gel is heated in an autoclave by slowly raising the temperature. This equally results in an increase in pressure. Both temperature and pressure are adjusted to values above the critical points of the solvent. After attaining the set conditions the temperature and pressure are kept constant for some time. The vapour is then slowly allowed to escape (venting) at constant temperature and this result in a pressure drop. When the system reaches the ambient pressure, the vessel is then cooled to room temperature. Aerogels obtained are hydrophobic. This method of drying may present some problems due to the high pressure and high temperature and the flammability of the solvent, usually alkanols.

In low temperature supercritical drying (LTSCD) the solvent in the gel is replaced by another which has a critical point close to ambient pressure. Liquid $\mathrm{CO}_{2}$ is most employed. The LTSCD can be achieved at low temperature $\left(<40^{\circ} \mathrm{C}\right)$ and moderate pressure, $<80$ bar [17].

The gel containing excess amount of solvent is placed in autoclave. Liquid $\mathrm{CO}_{2}$ is then pumped into the sealed vessel at $4{ }^{\circ} \mathrm{C}-10^{\circ} \mathrm{C}$ until the pressure reaches at $100 \mathrm{bar}$. The solvent extracted by the $\mathrm{CO}_{2}$ is then allowed to flow out by opening the outlet valve until $\mathrm{CO}_{2}$ completely replaces the solvent. The pump is then turned off and the temperature is raised above the critical temperature of $\mathrm{CO}_{2}$, about $40^{\circ} \mathrm{C}\left(\mathrm{T}_{\mathrm{c}} \mathrm{CO}_{2}\right.$ is $\left.31^{\circ} \mathrm{C}\right)$, keeping the pressure at 100 bar. When $\mathrm{CO}_{2}$ reaches its critical state, the system is slowly depressurized to reach ambient pressure. The system is then cooled down to the room temperature. Aerogels obtained by this method are hydrophilic.

b) Ambient pressure drying (APD)

Both high and low temperature super critical drying are expensive and there are safety concerns due to high temperature and pressure employed to reach the critical points [21]. The chemical durability of the LTSCD derived aerogel in the atmosphere would decrease because of their hydrophilic nature of the particles.

Brinker developed a more commercially attractive process in which drying is carried out at ambient pressure [22].

In APD, the water-alcohol mixture in the gel is first exchanged for a water-free solvent. Then the reaction with the silylating agent is carried out.

Ambient pressure drying involves surface modification (functionalisation) and network strengthening. What is done essentially is to minimize the capillary forces in the pores by influencing the contact angle between the pore liquid and the pore walls.

Silylation, the method of chemical modification of the inner surface of the gel, involves the substitution of $\mathrm{H}$ from the S-OH groups by the hydrolytically stable Si-R group through the oxygen bond, where $\mathrm{R}$ is a non-polar alkyl or aryl group. Dorcheh and Abbasi (2008) gave a pictorial description of the modification process as shown in Figure 2. It involves solvent exchange and surface modification using HMDSO (hexamethyldisiloxane)/TMCS (trimethylchlorosilane) with isopropyl alcohol solvent (IPA).

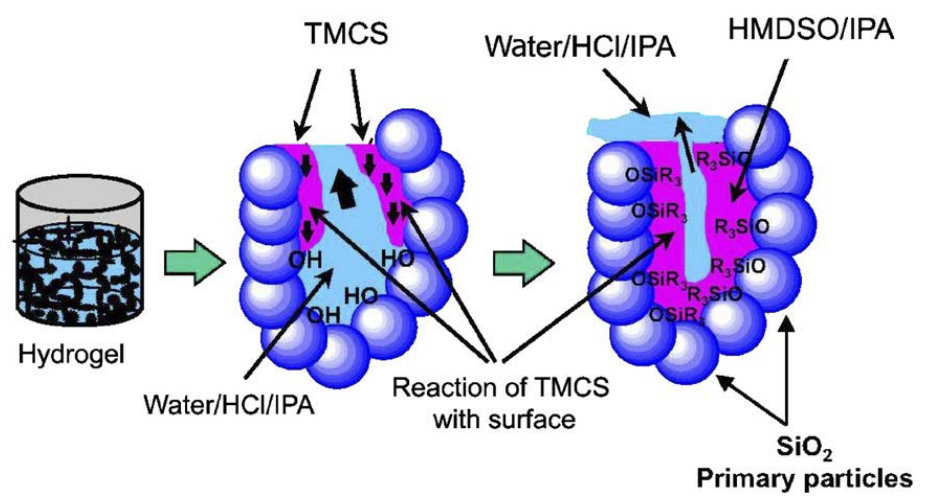

Figure 2. Schematic presentation of the reactions occurring during the modification process (Dorcheh and Abbasi, 2008). 
In APD, the water-alcohol mixture in the pores of the gel is first exchanged for a water-free solvent. Then the reaction with the silylating agent is carried out. Silylation results in the creation of surfaces with low energies thereby reducing surface tension. The resulting aerogel is hydrophobic. Examples of silylating agent that can alter the wetting properties of a surface are methyltrimethoxysilane (MTMS), hexamethyldisilane (HMDZ), dimethylchlorosilane (DMCS), dimethyldichlorosilane (DMDC), trimethylchlorosilane (TMCS), trimethyethoxysilane (TMES), and hexadecyltrimethoxysilane (HDTMS).

\section{Synthesis of Silica Aerogel from Rice Husk}

The need for cheaper aerogel synthesis has thrown up some materials as potential replacements for the more expensive precursors. It is expected that future researches will engage their possible use. One of such materials is rice husk, a waste product derived from rice processing.

Silica aerogel was prepared from rice husk ash with the aid of sodium hydroxide which was used to extract sodium silicate solution [23]. The resulting solution was then neutralized using sulphuric acid solution to obtain the silica gel. The gel was then washed with water and the solvent exchanged with ethanol. The aged alcogel was subsequently dried using supercritical carbon dioxide drying. The specific surface area of the aerogel was $597.7 \mathrm{~m}^{2} / \mathrm{g}$ with a bulk density of $38.0 \mathrm{~kg} / \mathrm{m}^{3}$. The pore diameter was between 10 and $60 \mathrm{~nm}$.

Nayak and Bera (2009) prepared silica aerogel using rice husk ash. The ash was boiled in $\mathrm{NaOH}$ solution to obtain sodium silicate solution which was then neutralized with nitric acid to form silica gel. The pore water of the gel was exchanged by ethanol and then the surface modification was carried out by aging the alcogel in tetraethyorthosilicate (TEOS)/ethanol solution. After aging, the solvent was replaced by n-heptane then dried at ambient pressure. The n-heptane solution added, due to its low surface tension, ensured that shrinkage in the gel network was greatly reduced. The aerogel obtained was crack-free with bulk density of $0.67 \mathrm{~g} / \mathrm{cm}^{3}$, porosity of about $80 \%$; total pore volume of $3.1 \mathrm{~cm}^{3} / \mathrm{g}$ and specific surface area of $273 \mathrm{~m}^{2} / \mathrm{g}$ [24].

Tadjarodi et al., (2012) prepared and characterised nano-porous silica aerogel from rice husk by drying at atmospheric pressure. As prepared by Nayak and Bera (2009), the gel was extracted with $\mathrm{NaOH}$. However, the neutralization was carried out using sulfuric acid to form hydrosol. The sodium sulphate in the gel was removed by washing the gel in de-ionised water for several hours after aging in TEOS for 24 hours. The water in the silica gel was then replaced by ethanol and then dried directly at atmospheric pressure for 10 hours at $40^{\circ} \mathrm{C}$ to yield silica aerogel. The silica aerogel obtained has a surface area of $315 \mathrm{~m}^{2} / \mathrm{g}$, pore volume of $0.78 \mathrm{~cm}^{3} / \mathrm{g}$ and porosity of $85 \%$ [25].

\section{Oil Absorption Study with Hydrophobic Aerogel}

Much work has not been done in the application of silica aerogel for crude oil absorption from water. In the work of Reynold et al., (2001), powdered $\mathrm{CF}_{3}$-functionalised aerogels were employed in absorbing crude oil

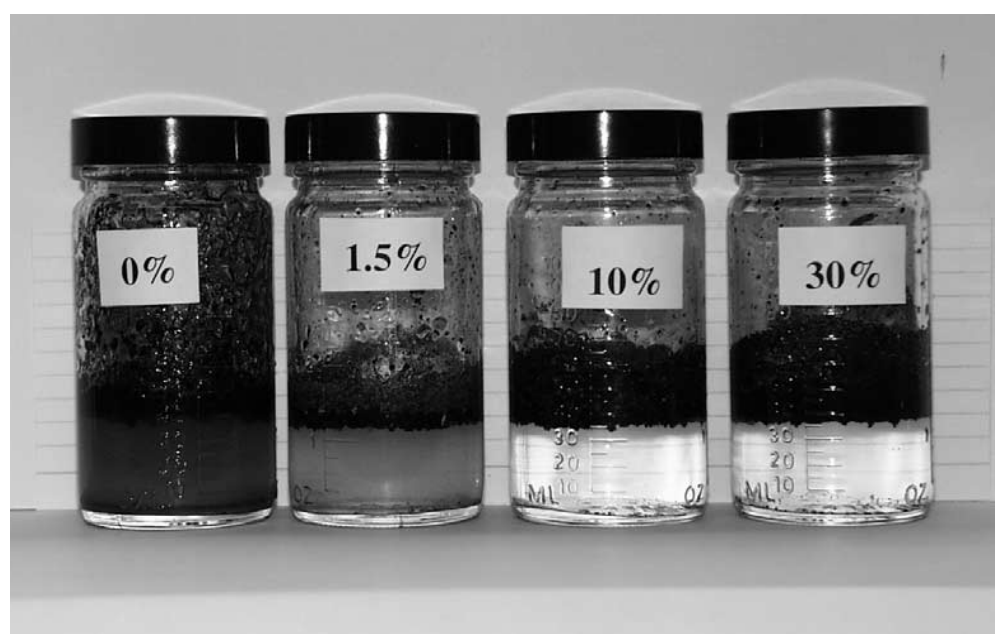

Figure 3. 30\%, 10\%, and $0 \% \mathrm{CF}_{3}$-aerogel mixed with Prudhoe Bay Crude oil with 3 wt\% $\mathrm{NaCl}$ (Reynold et al., 2001). 
from oil and salt-water mixture. The aerogel had been prepared by the sol-gel method using $\left(\mathrm{CH}_{3} \mathrm{O}\right)_{4} \mathrm{Si}$ using a functionalizing agent $\mathrm{CF}_{3}\left(\mathrm{CH}_{2}\right)_{2} \mathrm{Si}\left(\mathrm{OCH}_{3}\right)_{3}$ in $\mathrm{CH}_{3} \mathrm{OH}$ and $\mathrm{NH}_{4} \mathrm{OH}$ as the catalyst. Supercritical drying was carried out with $\mathrm{CH}_{3} \mathrm{OH}$ to obtain a hydrophobic aerogels. Regardless of the concentration of the functionalizing agent, the aerogels completely removed the oil from water as shown in Figure 3. The synthesized aerogel was capable of absorbing oil as much as 234 times its own weight. Silica aerogel granules, prepared using APD, were also used in absorbing various organic liquids from water [26]. Recently, magnetic and porous cellulose aerogel was developed which was able to absorb oil up to about 28 times its weight within 10 min [27]. The aerogel has the advantage of ease of removal using an external magnetic field as it is magnetic due to the incorporation of $\mathrm{Fe}_{3} \mathrm{O}_{4}$ nanoparticles.

\section{Conclusion}

The search for cheap and effective means of oil spill site remediation is of global interest. Sorbents have proved effective and it has been widely used. Silica aerogel has not been widely used. However, with the possibility of its synthesis with cheap raw materials, it could be a leading absorbent for oil spill remediation. Promising research area is in improving the properties of silica aerogel using ambient pressure drying.

\section{References}

[1] Andrew, S. (2014) The Oil Production Story: Pre- and Post-Peak Nations. BP Statistical Review of World Energy 2014. http://peak-oil.org/2014/06/the-oil-production-story-pre-and-post-peak-nations-3/

[2] Teal, J.M., Farrington, J.W., Burns, K.A., et al. (1995) The West Falmouth Oil Spill after 20 Years: Fate of Fuel Oil Compounds and Effects on Animals. Environmental Pollution, 87, 377. http://dx.doi.org/10.1016/0269-7491(95)90054-3

[3] Hussein, M., Amer, A.A. and Sawsan, I.I. (2008) Oil Spill Sorption Using Carbonized Pith Bagasse: Trial For Practical Application. International Journal of Environmental Science \& Technology, 5, 233-242. http://dx.doi.org/10.1007/bf03326017

[4] Angus, I. (2011) The Largest Oil Spills in History, 1901 to Present, 2011. http://chartsbin.com/view/mgz

[5] Kollewe, J. (2010) BP Oil Spill Costs Hits Nearly \$10 Billion. http://www.theguardian.com/environment/2010/sep/20/bp-oil-spill-deepwater-horizon-costs-10bn

[6] Oil Spills (2012) http://www.safewater.org/PDFS/resourcesknowthefacts/Oil_Spills.pdf

[7] Graham, P. (2010) Deep Sea Oil Spill Cleanup Techniques: Applicability, Trade-Offs and Advantages. www.csa.com/discoveryguides/oil/review.pdf

[8] Upson, S. (2010) Oil-Eating Microbes for Gulf Spill. Discovery News. http://news.discovery.com/tech/oil-eating-microbes-gulf-oil-spill.html

[9] Adebajo, M.O., Frost, R.L., Kloprogge, J.T., Carmody, O. and Kokot, S. (2003) Porous Materials for Oil Spill Cleanup: A Review of Synthesis and Absorbing Properties. Journal of Porous Materials, 10, 159-170. http://dx.doi.org/10.1023/a:1027484117065

[10] Karan, C.P., Regasamy, R.S. and Das, D. (2011) Oil Spill Cleanup by Structured Fibre Assembly. Indian Journal of Fibre \& Textile Research, 36, 190-200.

[11] Hussein, M., Amer, A.A., El-Maghraby, A. and Taha, N.A. (2009) Availability of Barley Straw Application on Oil Spill Cleanup. International Journal of Environmental Science and Technology, 6, 123-130. http://dx.doi.org/10.1007/bf03326066

[12] Hussein, M., Amer, A.A. and Sawsan, I.I. (2011) Heavy Oil Spill Cleanup Using Low Grade Raw Cotton Fibres: Trial for Practical Application. Journal of Petroleum Technology and Alternative Fuels, 2, 132-140. http://dx.doi.org/10.1007/bf03326017

[13] Choi, H.M. and Kwon, H. (1993) Oil Sorption Behavior of Various Sorbents Studied by Sorption Capacity Measurement and Environmental Scanning Electron Microscopy. Microscopical Research and Technology, 25, 447-455.

[14] Radetic, M., Ilic, V., Radojevic, D., Miladinovic, R., Jovic, D. and Jovancic, D. (2008) Efficiency of Recycled WoolBased Non-Woven Material for the Removal of Oil from Water. Chemosphere, 70, 525-530. http://dx.doi.org/10.1016/j.chemosphere.2007.07.005

[15] Patel, R.P., Purohit, W.S. and Suthar, A.M. (2009) An Overview of Silica Aerogels. International Journal of ChemTech Research, 1, 1052-1057.

[16] Sinko, K. (2010) Influence of Chemical Conditions on the Nanoporous Structure of Silicate Aerogels. Materials, 3, 
704-740. http://dx.doi.org/10.3390/ma3010704

[17] Dorcheh, A.S. and Abbasi, M.H. (2008) Silica Aerogel Synthesis, Properties and Characterization. Journal of Material Processing Technology, 199, 10-26. http://dx.doi.org/10.1016/j.jmatprotec.2007.10.060

[18] Yang, E. (2011) Fabrication and Preliminary Characterization of Hydrophobic Silica Aerogel Films for Oil Remediation Studies. B.A. Thesis, Pomona College, Claremont.

[19] Einarsrud, M.-A. (1998) Light Gels by Conventional Drying. Journal of Non-Crystalline Solids, 225, 1-7. http://dx.doi.org/10.1016/s0022-3093(98)00002-7

[20] Dai, S., Ju, Y.H., Gao, H.J., Lin, J.S., Pennycook, S.J. and Barnes, C.E. (2000) Preparation of Silica Aerogel Using Ionic Liquids as Solvents. Chemical Communications, 2000, 243-244. http://dx.doi.org/10.1039/a907147d

[21] Gurav, J.L. Jung, I.K., Park, H.H., Kang, E.S. and Nardagi, D.Y. (2010) Silica Aerogel: Synthesis and Application. Journal of Nanomaterials, 2010, 1-11. http://dx.doi.org/10.1155/2010/409310

[22] Brinker, C.J. and Scherer, W. (1990) Sol-Gel Science: The Physics and Chemistry of Sol-Gel Processing. Academic Press, Waltham.

[23] Tang, Q. and Wang, T. (2005) Preparation of Silica Aerogel from Rice Hull Ash by Supercritical Carbon Dioxide Drying. The Journal of Supercritical Fluids, 35, 91-94. http://dx.doi.org/10.1016/j.supflu.2004.12.003

[24] Nayak, J.P. and Bera, J. (2009) Preparation of Silica Aerogel by Ambient Pressure Using Rice Husk as Raw Materials. Transactions of the Indian Ceramic Society, 62, 1-4.

[25] Tadjarodi, A., Haghverdi, M. and Mohammed, V. (2012) Preparation and Characterization of Nano-Porous Silica Aerogel from Rice Husk Ash by Drying at Atmospheric Pressure. Material Research Bulletin, 47, 2584-2589. http://dx.doi.org/10.1016/j.materresbull.2012.04.143

[26] Reynolds, J.G., Coronado, P.R. and Hrubesh, L.W. (2001) Hydrophobic Aerogels for Oil-Spill Cleanup-Synthesis and Characterization. Journal of Non Crystalline Solids, 292, 127-137. http://dx.doi.org/10.1016/s0022-3093(01)00882-1

[27] Chin, S.F., Binti Romainor, A.N. and Pang, S.C. (2014) Fabrication of Hydrophobic and Magnetic Cellulose Aerogel with High Oil Absorption Capacity. Materials Letters, 115, 241-243. http://dx.doi.org/10.1016/j.matlet.2013.10.061 
Scientific Research Publishing (SCIRP) is one of the largest Open Access journal publishers. It is currently publishing more than 200 open access, online, peer-reviewed journals covering a wide range of academic disciplines. SCIRP serves the worldwide academic communities and contributes to the progress and application of science with its publication.

Other selected journals from SCIRP are listed as below. Submit your manuscript to us via either submit@scirp.org or Online Submission Portal.
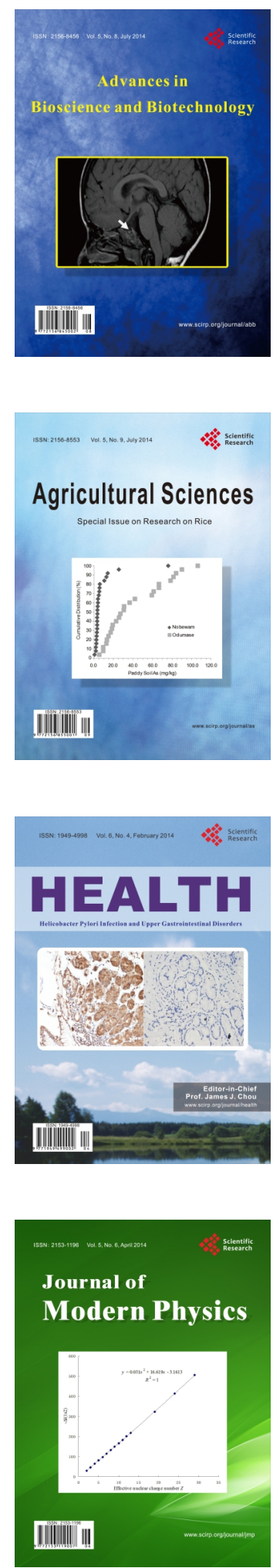
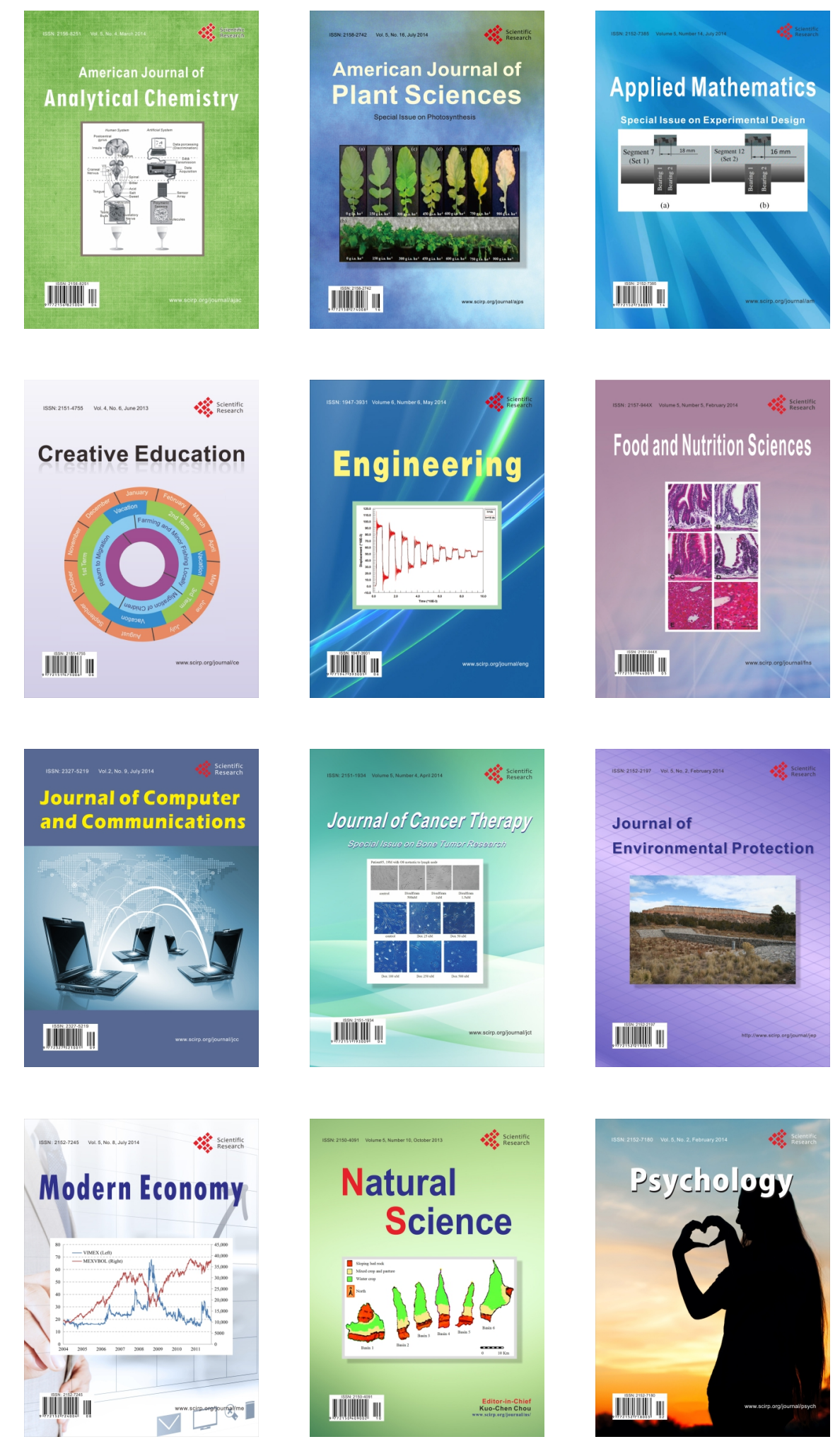